\title{
Embracing the Biosemiotic Perspective
}

\author{
Review of Biosemiotics: An Examination into the Signs of Life \\ and the Life of Signs by Jesper Hoffmeyer (translated \\ by Jesper Hoffmeyer and Donald Farvareau) University \\ of Scranton Press 2009 (Approaches to Postmodernity vol. 2) \\ 419 pages
}

\section{Bruce H. Weber}

Biosemiotics, as with any emerging research program, is undergoing a process of discussion as to its identifying underlying assumptions, phenomena to be addressed, and the types of problems, including the nature of successful solutions, which engage the community of scholars in the field. This process includes developing edited books in which the different strands within the field are represented as well as a journal to disseminate such discourse. Edited volumes, such as Introduction to Biosemiotics: The New Biological Synthesis, as well as this journal are examples (Barbieri 2008; see also Witzany 2007). Four main approaches to biosemiotics have been identified (Barbieri 2008). One is based upon the concept of Howard Pattee of an epistemic threshold as a boundary where local matter has intrinsic properties governed by universal laws but also is about something and stands for something else in an emergent process (Pattee 1969, 1972, 2001). A second derives from the work of Marcel Florkin, which drew upon the distinction of Ferdinand de Saussure of signifier and signified (Florkin 1974). The third is based upon the organic code concepts of Marcello Barbieri in which a semiotic threshold is exceeded by cellular systems that act as code makers rather than interpreters (Barbieri 2003). A fourth approach originated in the work of Thomas Sebeok in which ideas of Charles Saunders Peirce about triadic interactions including interpretation are applied to living systems (Sebeok 1972, 2001).

B. H. Weber (西)

Department of Chemistry \& Biochemistry, California State University Fullerton, Fullerton, CA 
The author of this seminal and important book being reviewed is Jesper Hoffmeyer, Professor of Biochemistry at the University of Copenhagen and one of the main contributors to the emerging field of biosemiotics. This new volume builds upon his previous contribution Signs of Meaning in the Universe in which he provided his first extended articulation of his approach to applying semiotic principles to living systems that has appeared in over thirty publications over the past thirty some years (Hoffmeyer 1996, 2009). Hoffmeyer, along with Claus Emmeche, Soren Brier, and Kalevi Kull, have formulated what is often called the Copenhagen school of biosemiotics, although the Americans Terrence Deacon and Stanley Salthe are also self-described participants in this endeavor, all of whom build upon the conceptual insights of Charles Saunders Peirce. Hoffmeyer's new contribution provides an introduction to the field of biostemiotics, articulates the vision of the school of biosemiotics to which he belongs, and addresses the issues that distinguish his approach from the other three main versions of biosemiotics, even as he draws usefully upon many of their insights. Hoffmeyer seeks to set out the background assumptions and identify the paradigmatic problems and outline the form of their solutions for the research program of biosemiotics. Such a program should not only bring conceptual coherence to a range of previously disparate phenomena and provide explanations by a robust theory, but also should guide research to engage new problems and phenomena identified by the program.

Hoffmeyer seeks to develop an enriched biological theory that is evolutionary and fully naturalistic, but one that also addresses the real emergent complexity of biological systems and their behavior and not simply reduce them to Cartesian, Newtonian or even Boltzmannian mechanical and de-semiotized entities. He joins a number of biologists who seek an expanded, or extended evolutionary synthesis (Eldredge 1985; Brooks and Wiley 1986; Wicken 1987; Gould 2002). Such a process, as with the formation of the original Modern Evolutionary Synthesis, or neo-Darwinism, took over two decades and involved a major and careful reworking of the background assumptions and systems dynamics that informed the new theory and research program and if indeed a new evolutionary synthesis emerges it will likely also take decades (Depew and Weber 1995). In addition to employing the tools of complex systems dynamics (including nonlinear dynamics, non-equilibrium thermodynamics, hierarchy theory, and processes of emergence) many have suggested the need to incorporate information theory (Gatlin 1972; Brooks and Wiley 1986, 1988; Collier 1986). Metaphors of codes, language, and information were introduced by molecular biologists. Although there was a mathematical theory of information available, which helped provide credibility to such usage, there was not a careful conceptual or philosophical analysis of how to apply information theory. Despite extensive use of information theory by Gatlin, Brooks, Collier, Wicken, and Wiley, there has been a sense of its limited utility because of issues concerning biological function and meaning (Weber et al. 1989; Hariri et al. 1990). The most successful application of information theory has been to use it as an index, or metric, of the complexity of relationships and to track processes in ecosystems as pioneered by Robert Ulanowicz (1986, 1997, 2009a). But even here the limitation is apparent and the need for a most robust conceptual scheme is clear (Ulanowicz 2009 b). On the one hand, the shift to background assumptions of complex systems dynamics provides a more friendly intellectual environment for biosemiotic 
approaches and on the other biosemiotics can enrich concepts of biological information processing, function, and meaning without reifying information as DNA.

Hoffmeyer takes as his premise that biology must acknowledge a sense of self, and that life and semiosis emerged together. His goal is to develop the tools for theoretical biology that incorporate biosemiotics as well as to contribute to the development of a general theory of semiosis and its implications for natural philosophy. He sets out to do this in three stages. First, he presents bioshemiotics in a Peircean perspective and applies it to the problem of the origin of life. Second, he explores how biosemiotics can clarify processes of coding and cellular biochemistry, including developmental processes which have been until recently marginalized in the Modern Evolutionary Synthesis. Third, he examines how biosemiotics could be applied to human behavior and culture and specifically to the problem of the origin of language. The focus is on two of the main challenges of natural philosophy: the emergence of life and the emergence of mind. The philosophical stance is that process rather than matter is fundamental. Hoffmeyer's ontology is one of a hierarchy of process organization. Biosemiotics is defined as an interdisciplinary project that views life as grounded in semiotic processes of sign relations and their signification. "Life is composed of molecules, which manifest themselves as signs" (Hoffmeyer 2009, 15). Indeed, one of the strengths of this book is the extent to which Hoffmeyer grounds his presentation in apt and illustrative molecular and biochemical detail even as he makes his more general theoretical and philosophical points.

Hoffmeyer is particularly perspicuous in his discussion of biological membranes and their role in defining self and non-self, in transport of metabolites, in signal transduction, in serving as an interface and semiotic bridge. In eukaryotes, with their organelles, there are membranes within membranes, and in multi-cellular organisms membranes are essential as communicative surfaces affecting gene expression during development. DNA is not the controlling element but a coded array whose function is growing the embryo and producing what is needed, "the biological orchestration of an organism is created by a well-tuned symphony of biosemiotic relationships across membranes ..." rather than a simple readout of controlling genes (Hoffmeyer 2009, 31). That is, living cells use DNA to construct the organisms rather than the reverse. For Hoffmeyer, understanding the emergence of life requires understanding how self-reference and other-reference arose within a membrane system (see Weber 2000, 2007 on the possible role of membrane-like structures in the origin of life). Hoffmeyer suggests a five-step process: 1. autocatalytic closure or self-sufficiency (see Kauffman 1993, 2000); 2. closed membranes with concomitant asymmetry that underlies life-sustaining semiositic and chemiosmotic processes; 3. emergence of higher-order autocatalysis in ensembles of membrane units; 4. a self-referential, digital re-description in DNA and/or RNA of the analog protein components; 5. membranes become interfaces or other-reference systems serving to integrate selfreference and other-reference. With the achievement of the last three steps the characteristic property of living systems of agency emerges. Also, the achievement of information-bearing macromolecules serving to stabilize information is crucial but secondary in the process of the emergence of living systems. In this view, membranes have efficient causality whereas genomes have formal causality. This 
biosemiotic view is consistent with the approach of complex systems dynamics to the problem of the emergence of life and taken together provides a richer conceptual context for origin-of-life research (Weber 1998, 2000, 2007).

Hoffmeyer spends a chapter discussing the general conclusions of Peirce's philosophy and how it can serve as a foundation for biosemiotic thought. His presentation of Peirce's thought is more clear and lucid than many, and gives a view of Peirce as espousing final cause as the end state of a natural process such as randomness and irreversibility. Hoffmeyer goes on to distinguish final causes from biological functionality, which is the result of a trait's biological role in the context of the historical circumstances of the lineage. He also sees natural selection as part of a deeper dynamic in nature, one that interacts with self-organization in ways that seem similar to an evolutionary theory informed by complex systems dynamics (Weber and Depew 1996). In addition to illustrating the sign-object-interpretant triad in biological systems, Hoffmeyer argues that Peirce's notion of habit is a form of self-organization, and further lays out Peirce's three categories as foundations for semiosis. Hoffmeyer introduces the term 'semiotic causality' that he defines as "bringing about things under the guidance of interpretation in a local context" (Hoffmeyer 2009, 62). He sees biosemiosis as "the never-ending stream of sign processes that regulate and coordinate the behavior of living systems, depend[ing] on the special receptivity that evolutionary systems over time have developed towards selective features of their environment" (Hoffmeyer 2009).

A whole chapter is devoted to the implications of the importance of code-duality in living systems. The proteome and other molecular components of living systems work using analog codes, but DNA and the various RNAs use digital codes. Contra the assertions of Richard Dawkins that nucleic acid properties are enough to define life, Hoffmeyer argues that "to ascribe such agency to DNA is highly contraindicated from the chemical point of view" (Hoffmeyer 2009, 78). This is because DNA is largely chemically inert, making it suitable as the "memory" molecule. From the biosemiotic perspective, the digital code of DNA is based upon symbolic signs, whereas the analog codes of proteins are based upon icons and/or indices, an issue Hoffmeyer further explores in another chapter. Drawing upon insights from Gregory Bateson and Howard Pattee, Hoffmeyer observes that, "Life must be understood as semiotic survival - survival via a fundamental code-duality" (Hoffmeyer 2009, 80). Life requires self-reference, which is provided by the re-description provided by this code duality. An important consequence of this is that Lamarackian mechanisms are blocked due to the different roles of the codes and the passivity of DNA. Also, the developmental process is seen as one involving a complex and active translation of the digital code of DNA into the analog code of proteins, but in which the DNA is but one of several important developmental resources. Another advantage of the digital code is that it can contain 'meta-messages' in the DNA that provides for regulation of gene expression. Even if some sort of semiosis can exist prior to life, with the emergence of living systems there emerges a new kind of 'semiotic freedom' that allows them to "systematically recognize and exploit (interpret) important regularities (causal relations) in their surroundings, and in doing so, living systems gain access to the world of genuine triadic sign process" (Hoffmeyer 2009, 84). Because of the code duality living systems have a dual causality. Rather than attempting to make nucleic acids or proteins more causally fundamental, both 
systems need to be seen as mutually entailing but with different causal roles. Hoffmeyer writes that "replicators exert formal causality, while interactors [proteins and the rest of the biochemical components] exert efficient causality. Final causality, sensu Peirce, makes use of both tools and is, in this context, connected to life's codedual structure" (Hoffmeyer 2009, 97). Hoffmeyer likens this code/causal duality to the performance of a string quartet in which the score is digital but the actual production of the music is analog.

Hoffmeyer goes on to explore in apt detail a number of complex biological examples of semiotic processes in living systems, which, he admits, can be explained retrospectively by traditional notions of natural selection. But he argues that something more is needed to understand how such complex, integrated, semiotic systems emerge. "[O]utside of biosemiotics, the idea that a nondigitalized but relatively stable semiotic scaffolding of these integration mechanisms might establish itself is a strongly underestimated possibility, if it is considered at all" (Hoffmeyer 2009, 101). Here is an example of the potential for biosemiotics not just to organize existing knowledge but to frame new kinds of questions and generating new lines of investigation. This potential is cashed out in a chapter on developmental, or epigenetic, processes formulated in the biosemiotic perspective. Hoffmeyer shows how this kind of approach is conducive to conceptual coherence but also allows the synthesis of biosemiotics with a number of other perspectives, such as those of Developmental Systems Theory. It also could facilitate the incorporation of developmental and evolutionary biology since through the digital code organisms are "in communication" with their ancestors and offspring and through the analog code organisms take part in the local semiosphere. The developmental process itself can be perspicuously re-described as a self-organizing semiotic process in which morphogenesis is controlled by cytoplamsic factors. This is consistent with the view of Barbieri in which both DNA memory but also epigenetic cell memory play causal roles in embryogenesis through such mechanisms as chromatin marking and DNA methylation (Barbieri 2003). Hoffmeyer argues that embryological and neurobiological research support the proposition that "genes function as signposts in a dynamic interplay with each other and with the network of proteins and membranes in the growing embryo. It is not the genes themselves but their interplay and integration in the cell that counts" (Hoffmeyer 2009, 131, emphasis in original). It is the emergent organization of processes that forms the context of the on-going semiosis in living cells and organisms. It is one of the strengths of Hoffmeyer's exposition that he can move from single cells to multi-cellular organisms undergoing development over a lifecycle to complex ecosystems in a coherent and comprehensive manner within the biosemiotic perspective. Indeed, one can well imagine that taking the biosemiotic turn could provide the basis for producing a textbook of biochemistry that would gain in conceptual coherence and organization integrating metabolism with complex signal transduction and information processing.

The case that Hoffmeyer makes would be persuasive even if it went no further, but he goes on to examine broader issues, such as the role of behavior in animals and their evolution as well as the dynamics of whole ecosystems. He treats the Baldwin effect, whereby adaptive behaviors, if learned and effective over generational time, can come to be grounded and facilitated by genetic changes via standard 
evolutionary mechanisms, in biosemiotic terms that provide new insights (see the collection of essays in Weber and Depew 2003 on the status of the Baldwin effect in current research). More speculatively, Hoffmeyer shows how biosemiotics can help resolve the problem of qualia, or of the subjective experience of animals. He connects this with the Umwelt theory of Jakob von Uexküll about the perceptual world of an organism, which today might more aptly be described as its virtual reality. Hoffmeyer admits that as currently deployed complex systems dynamics theory does not account for qualia or semiosis but proposes that biosemiotics as it matures should be able to utilize complex systems dynamics to produce a more complete account. He also examines the claims of artificial-life research that he suspects will flounder unless semiosis is incorporated.

The internalist perspective inherent in the qualia of organisms, which is their experiential component, is an integral aspect of living entities and leads Hoffmeyer to propose the concept of 'the semiotic niche' as a generalization of this internalist viewpoint, one that is consistent with Peircean philosophy, in which all the sign processes important to the survival of an organism are included. Hoffmeyer shows how precise questions for further investigation can be posed by asking about the congruence of an organism's Umwelt and its semiotic niche. What Hoffmeyer asks us to do is not to dismiss the problem of qualia because of its difficulty or because it seems inconsistent with the received view of science, but rather than we accept it as a biological phenomenon that needs an explanation of its evolutionary origin and function, questions about which biosemiotics can help to formulate.

In a chapter on endosymbiosis, Hoffmeyer distinguishes the different semiotic logic of prokaryotes and of eukaryotic multi-cellular organisms. The prokaryotes have various mechanisms of signal exchange such that they form a kind of global semiosphere. In contrast, eukaryotes are isolated beings, but what they lost in horizontal communication they have gained through a rich panoply of non-digital biochemical and behavioral signs. "The transition from prokaryotic to eukaryotic life forms thus exemplifies a general principle pertaining to emergent processes - ie, that in emergent processes, freedom of possibility will always be constrained at the simpler level in order to allow an altogether new kind of freedom to appear and unfold at a more complex level. The emergence of multi-cellular life and social life are but two more examples of this fundamental dynamical principle" (Hoffmeyer 2009,258 , emphasis in original). This is an important insight in itself and one that has more general applicability.

The emergence of true language in human evolution is addressed in the penultimate chapter. Whereas the emergence of life can be viewed as an endosemiotic process, the emergence of language reflects an exosemiotic one. In the penultimate chapter Hoffmeyer addresses issues of human evolution and semiotic activity, particularly the question of the emergence of language. Because of human symbolic activity and culture we do more than participate in an Umwelt, we live in a subjective world. Here, of course, the semiotic approach is at its more naturally effective. The key for understanding human evolution, in Hoffmeyer's view, is in understanding the emergence of language. Indeed, language, along with life itself, represents the two major emergences. Clearly here biosemiotics has an obvious contribution to make to theoretical biology, particularly through the semiotically informed proposals of Deacon in his seminal The Symbolic Species, 
whose arguments Hoffmeyer follows (Deacon 1997). The hard problem here is the discontinuity of human and primate communication. Hoffmeyer makes a distinction between two kinds of discontinuity: expressive sounds/meanings and systems of expressive sounds/meanings; it is the latter that is crucial. According to Deacon, what is special in humans is symbolic reference. From this perspective, Hoffmeyer sees the final stages of brain development as guided by epigenetic semiosis, rather than being genetically programmed and determined, even though the crucial evolutionary changes in the human lineage were genetically underwritten, probably by a Baldwinian-type mechanism. Hoffmeyer argues that there are limitations to the Saussure-inspired semiotics due to a bias towards linguistic and social communication. Deacon's more robust account of the emergence of language is informed by the Peircen understanding of the role of the interpretant put in evolutionary perspective. "It is exactly here that Peirce's well-known trichotomy reflecting the three fundamentally different ways signs may refer to their object-i.e., the major categorical trichotomy of icon, index, and symbol-shows itself to be the key that unlocks the understanding as to what joins human language to the evolutionary lineage of other animal systems, and what makes it unique. For only humans are able, in natural settings, to communicate using high-order tools of symbolic reference ..." (Hoffmeyer 2009, 283, emphasis in original).

Hoffmeyer uses a biochemical example to point out that for bacteria some enzymes involved in ATP degradation do not distinguish between ATP and cAMP, such that if cAMP binds instead of ATP it acts as a competitive inhibitor, thereby disrupting energy metabolism. In this case cAMP is acting as an icon for ATP and the concentration of cAMP acts as an index for a deficiency in energy metabolism. Later in evolution, in multi-cellular metazoans, cAMP came to function as a symbol. Hoffmeyer concludes that symbolic reference appeared in evolution well before humans, indeed he avers that DNA and RNA exhibit symbolic reference. The key difference between the cAMP example and human language is that the former is endosymiotic whereas the latter involves exosymiotic processing of symbols between individuals. Deacon's distinction, which Hoffmeyer accepts, is that nonhuman animals may use iconic and indexical reference, but only humans evolved to communicate through symbolic reference. This view of language represents an account of the emergence of a sophisticated new semiotic resource that grew out of the rich web of somiotic activities in living systems; it is a fusion of evolutionary anthropology, neuroscience, and biosemiotics. It makes particular sense within the context of the characteristic dynamics of complex systems. At a deep level there are likely important insights to be gained by thinking about the 'semiodynamics' of the processes of the symbolic emergence in both the origin of life and of language.

Hoffmeyer considers that taking the biosemiotic turn will ultimately have major implications for the philosophy and practice of science. He raises the issue in terms of the type of Peircean biosemiotics he espouses and in particular why bother with triadics when most of our understanding has been developed by a biological science based upon a dyadic approach. He responds by pointing out that molecular biology and biochemistry have already used metaphors of information and increasingly are discussed in what have to be considered as biosemiotic terms, even if the practioners of these fields have yet to acknowledge this. Further, "evolution has worked an 
interactive, triadic logic into the organization of life processes - one that subsumes the otherwise organismic chaos of biochemical activities under its controlling agency. Dyadic modeling (and dyadic thinking) simply does not suffice as an explanatory strategy here. Thus, even though biochemistry as an experimental discipline may still, and for a long time, profit from basing its lab-oriented piece work on a dyadic simplification of naturally occurring biological chemistry, the discipline ought to recognize the approach for what it is - a very practical but necessarily artificial and incomplete method" (Hoffmeyer 2009, 317, emphasis in original). The importance of biosemiotics is for the development of a more robust theory of biochemistry and of biology more generally. Practicing scientists will incorporate biosemiotics into their theories if it provides a better explanatory framework and if it helps formulate new theories and lines of research.

The other reservations, Hoffmeyer acknowledges, include concern about perceived anthropomorphism and teleology. These are issues of concern to philosophers of science that can be ameliorated and dealt with by careful usage and applications of biosemiotics in contexts where it is clear that these concerns do not apply (see Allen et al. 1998 for the former and Ulanowicz forthcoming for an example of the latter). Used with discretion and discernment biosemiotic approaches have the potential to enrich biological theory. Further, it has the potential to connect disparate phenomena and to help in the formulation of a general theory of emergence.

Throughout the book, Hoffmeyer successfully navigates a course between the Scylla and Charybdis of vitalism and reductionism by fully engaging the complexity of living systems and the fully natural processes of emergence and evolution. He also makes a distinction, that makes a difference, between a pansemiosis, which sees semiotic aspects of living systems as nothing but that seen in physical systems, and an anthroposemiosis, which reads the special characteristics of the human mind into all nature. Hoffmeyer does a remarkably good job of keeping his balance amid a variety of such slippery slopes. He thus fully accepts the phenomenon of evolution and the important role that natural selection plays, but he also agrees with those who argue that the Modern Evolutionary Synthesis is an incomplete, an unfinished synthesis. Genes and natural selection are important in evolution, but also are development, self-organization, emergent phenomena, and, of course, semiotic interactions at various levels.

\section{References}

Allen, C., Bekoff, M., \& Lauder, G. (eds). (1998). Nature's purposes: Analyses of function and design in nature. Cambridge: MIT.

Barbieri, M. (2003). The organic codes: An introduction to semantic biology. Cambridge: Cambridge University Press.

Barbieri, M. (ed). (2008). Introduction to biosemiotics: The new biological synthesis. Dordrecht: Springer.

Brooks, D. R., \& Wiley, E. O. (1986). Evolution as entropy: Toward a unified theory of biology. Chicago: University of Chicago Press.

Brooks, D. R., \& Wiley, E. O. (1988). Evolution as entropy: Toward a unified theory of biology (2nd ed.). Chicago: University of Chicago Press.

Collier, J. (1986). Entropy in evolution. Biology \& Philosophy, 1, 5-24. 
Deacon, T. W. (1997). The symbolic species: The co-evolution of language and the brain. New York: Norton.

Depew, D. J., \& Weber, B. H. (1995). Darwinism evolving: Systems dynamics and the genealogy of natural selection. Cambrdige: MIT.

Eldredge, N. (1985). Unfinished synthesis: Biological hierarchies and modern evolutionary thought. New York: Oxford University Press.

Florkin, M. (1974). Concepts of molecular biosemiotics and molecular evolution. In M. Florkin \& E. H. Stotz (Eds.), Comprehensive biochemistry, vol 29 (pp. 1-124). Amsterdam: Elsevier.

Gatlin, L. (1972). Information and the living system. New York: Columbia University Press.

Gould, S. J. (2002). The structure of evolutionary theory. Cambridge: Harvard University Press.

Hariri, A., Weber, B. H., \& Olmsted, J. (1990). On the validity of Shannon-information calculations for molecular biological sequences. Journal of Theoretical Biology, 147, 235-254.

Hoffmeyer, J. (1996). Signs of meaning in the universe. Bloomington: Indiana University Press.

Hoffmeyer, J. (2009). Biosemiotics: An examination into the signs of life and the life of signs. Scranton: University of Scranton Press.

Kauffman, S. A. (1993). The origins of order: Self-organization and selection in evolution. New York: Oxford University Press.

Kauffman, S. A. (2000). Investigations. New York: Oxford University Press.

Pattee, H. H. (1969). The physical basis of coding and reliability in biological evolution. In C. H. Waddington (Ed.), Toward a theoretical biology, vol 1 (pp. 67-93). Edinburgh: Edinburgh University Press.

Pattee, H. H. (1972). Laws and constraints, symbols and languages. In C. H. Waddington (Ed.), Toward a theoretical biology, vol 4 (pp. 248-258). Edinburgh: Edinburgh University Press.

Pattee, H. H. (2001). The physics of symbols: bridging the epistemic cut. BioSystems, 60, 5-21.

Sebeok, T. A. (1972). Perspectives in zoosemiotics. The Hague: Mouton.

Sebeok, T. A. (2001). Biosemiotics: its roots, proliferation, and prospects. Semiotica, 134, 68.

Ulanowicz, R. E. (1986). Growth and development: ecosystems phenomenology. New York: Springer.

Ulanowicz, R. E. (1997). Ecology, the ascendent perspective. New York: Columbia University Press.

Ulanowicz, R. E. (2009a). A third window: Natural life beyond Newton and Darwin. West Conshohocken: Templeton Foundation Press.

Ulanowicz, R.E. (2009b). Stepping stones to biosemiosis. Process Ecology, in press.

Weber, B. H. (1998). Emergence of life and biological selection from the perspective of complex systems dynamics. In G. Van de Vijver, S. N. Salthe \& M. Delpos (Eds.), Evolutionary systems: Biological and epistemological perspectives on selection and self-organization (pp. 59-66). Dordrecht: Kluwer.

Weber, B. H. (2000). Closure in the emergence and evolution of life. Annals of the New York Academy of Sciences, 901, 132-138.

Weber, B. H. (2007). Emergence of life. Zygon, 42, 837-856.

Weber, B. H., \& Depew, D. J. (1996). Natural selection and self-organization: dynamical models as clues to a new evolutionary synthesis. Biology \& Philosophy, 11, 33-65.

Weber, B. H., \& Depew, D. J. (eds). (2003). Evolution and learning: The Baldwin effect reconsidered. Cambridge: MIT.

Weber, B. H., Depew, D. J., Dyke, C., Salthe, S. N., Schneider, E. D., Ulanowica, R. E., et al. (1989). Evolution in thermodynamic perspective: an ecological approach. Biology \& Philosophy, 4, 373-405.

Wicken, J. S. (1987). Evolution, information, and thermodynamics: Extending the Darwinian program. New York: Oxford University Press.

Witzany, G. (ed). (2007). Biosemiotics in transdisciplinary contexts. Vilnius: Umweb. 